\title{
The balancing act of the liver: tissue regeneration versus fibrosis
}

\author{
Lucía Cordero-Espinoza and Meritxell Huch \\ Wellcome Trust/CRUK Gurdon Institute, Wellcome Trust-Medical Research Council Stem Cell Institute, and Department of Physiology, Development and Neuroscience, University of Cambridge, \\ Cambridge, United Kingdom.
}

Epithelial cell loss alters a tissue's optimal function and awakens evolutionarily adapted healing mechanisms to reestablish homeostasis. Although adult mammalian organs have a limited regeneration potential, the liver stands out as one remarkable exception. Following injury, the liver mounts a dynamic multicellular response wherein stromal cells are activated in situ and/ or recruited from the bloodstream, the extracellular matrix (ECM) is remodeled, and epithelial cells expand to replenish their lost numbers. Chronic damage makes this response persistent instead of transient, tipping the system into an abnormal steady state known as fibrosis, in which ECM accumulates excessively and tissue function degenerates. Here we explore the cellular and molecular switches that balance hepatic regeneration and fibrosis, with a focus on uncovering avenues of disease modeling and therapeutic intervention.

\section{Introduction}

Regeneration is the ability to recreate original tissue architecture and function following damage without leaving a scar (ref. 1 and Figure 1). Far from mythological contrivance, this mechanism is very much present in nature yet varies dramatically across metazoan species (2) and with age (3); think of an axolotl or a salamander, which seamlessly regrows its limbs after amputation (Figure 1A). Mammals share a similarly remarkable ability to regenerate tissue during prenatal development but lose most of it in adulthood. Adult injuries are repaired as opposed to regenerated, replacing functional tissue parenchyma with a meshwork of extracellular matrix (ECM). The liver is one of the few organs in the mammalian body that defy this paradigm, as it can regenerate efficiently from a wide range of physical and toxic injuries (4). Adult regenerative powers are nonetheless finite, even in the liver. The process of regeneration following an acute insult is characterized by a transient cellular and molecular response whose resolution is as important as its emergence for the tissue to reestablish homeostasis (5). It thus follows that switching-off mechanisms must be embedded within the process of wound healing because the same pathways that promote regeneration, when overstimulated, progressively drive scarring and degeneration of the tissue in a process known as fibrosis (6). As a parallel to fibrosis mechanisms, we can think of how cell proliferation, when uncontrolled, may eventually progress into tumorigenesis. In this Review we will explore the delicate balance that exists between regeneration and fibrosis, with a special focus on the liver as an organ that is familiar with both processes.

Conflict of interest: The authors have declared that no conflict of interest exists. Reference information: J Clin Invest. 2018;128(1):85-96.

https://doi.org/10.1172/JCI93562.

\section{Liver regeneration}

In the absence of injury, the liver epithelium is maintained by the slow turnover of hepatocytes (7) and/or ductal cells (8) within their own compartments. Experiments in rats have shown that between $0.2 \%$ and $0.5 \%$ of hepatic cells are dividing at any given time point (9). However, this mitotic quiescence is misleading because, if challenged, the hepatic tissue displays a remarkable capacity for regeneration and reinstalls homeostasis within days. Reminiscent of limb regrowth in amphibians, up to $70 \%$ of the liver can be surgically resected and the organ will grow back to its original size through compensatory proliferation of both the epithelium (hepatocytes and biliary duct cells) and the stroma, composed of Kupffer cells (macrophages), liver sinusoidal endothelial cells (LSECs), hepatic stellate cells (HSCs), and portal fibroblasts (10). Notwithstanding, the hepatectomized liver is not considered injured nor "damaged"; regeneration occurs from the unscathed lobe(s) as a result of the organ's ability to sense insufficient size (Figure 1B). The hepatectomy-induced healing response thus has clinical relevance for live-donor transplants and tumor resections but is of less consequence to chronic liver pathologies like nonalcoholic fatty liver disease and cirrhosis, which account for high rates of morbidity worldwide $(11,12)$. Hepatic epithelial cells, hepatocytes in particular, are susceptible to pathologies of this sort because of their daily exposure to exogenous and endogenous toxins (alcohol, viruses, and fatty acids, among others) as part of their metabolic and digestive functions. This has subjected the tissue to a unique evolutionary pressure to develop robust, yet not infallible, mechanisms of regeneration against toxic injury (Figure 1C).

Epithelial progenitor cells are thought to compensate for tissue loss in many adult tissues, in what has been hypothesized as a reiteration of developmental mechanisms (13-17). In the liver, this idea resonates loudly, considering that hepatoblasts are bona fide bipotential precursors of bile duct cells and hepatocytes during organogenesis (14). Pioneering work in adult rat livers has 
A Lower vertebrates

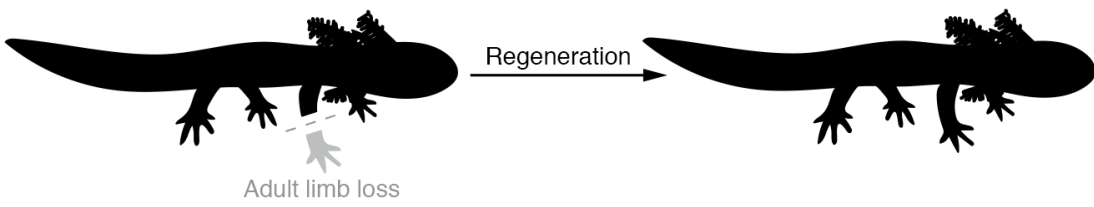

B Mammals (liver)
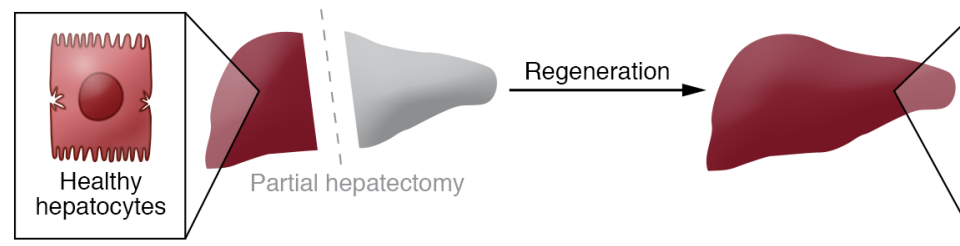

C
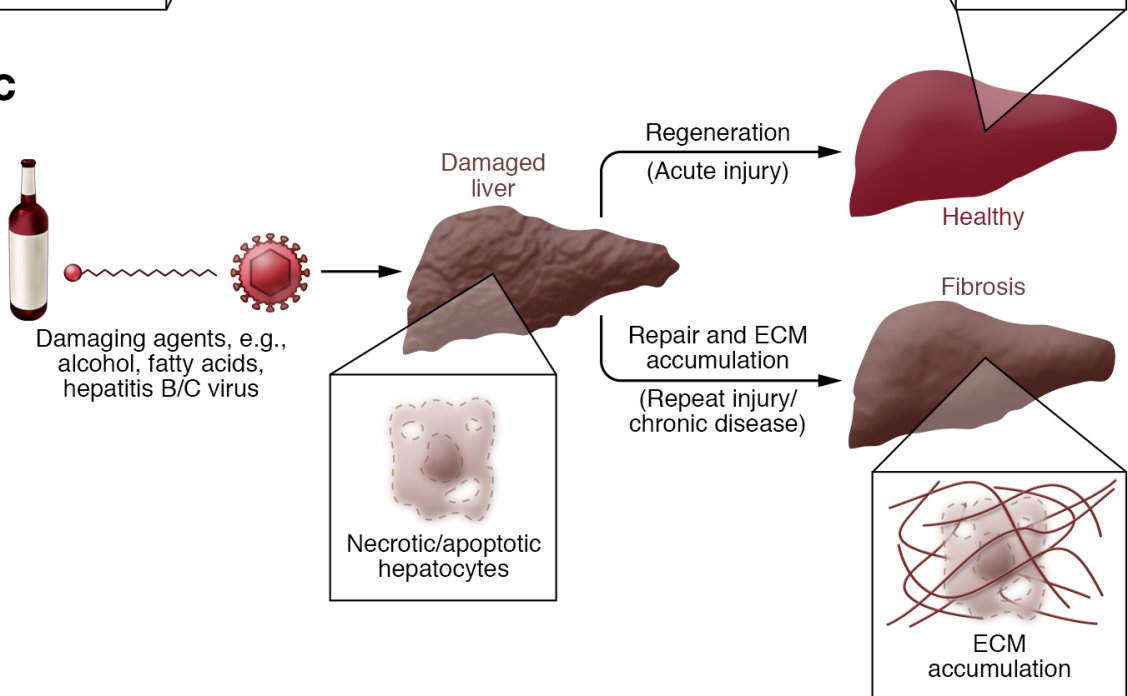

Figure 1. Coping with injury: regeneration versus repair. (A) Lower vertebrates, such as axolotls, salamanders, and fish, are able to regenerate severed limbs through a process that reconstitutes original tissue anatomy and function without leaving a scar (a meshwork of ECM). Mammals may similarly regenerate complex tissues during embryogenesis, but lose most of this capacity in adulthood. (B) The liver is one of the few adult mammalian organs that retains a remarkable ability to regenerate itself. Resection of up to $70 \%$ of the liver mass via partial hepatectomy leads to compensatory growth from the intact tissue and fully restores organ size in a matter of days, similarly to axolotl limb regrowth. However, the hepatectomized liver is typically not injured or "damaged," and regeneration is a result of the organ's ability to sense insufficient size. (C) The liver may also regenerate following injury by exogenous and/or endogenous agents (e.g., alcohol, hepatitis B/C viruses, fatty acids) that cause hepatocyte death. This process is characterized by an inflammatory reaction and ECM synthesis/remodeling. However, if the dam aging insult persists, the tissue will be repaired instead of regenerated, resulting in excessive scarring, known as fibrosis, that alters histoarchitecture and hinders optimal tissue function. also shown a robust damage-induced expansion of "oval-looking" cells expressing developmental markers and pulse-chasing into both mature hepatocytes and biliary ducts (18-20). Nonetheless, the cell of origin and the regenerative potential of these cells remain contentious to this very day. Evidence supporting biliary ancestry comes from lineage tracing experiments in Sox9-CreER (21) and Opn-CreER (22) mice, and from the fact that whole ductal tree fragments (23) or ductal marker-enriched (e.g., $\mathrm{EpCAM}^{+}$, MIC1-1C3 ${ }^{+}, \mathrm{CD}_{24}{ }^{+}, \mathrm{CD} 133^{+}$) single cells self-renew in vitro as 2D monolayers or 3D organoid cultures (24-27) while maintaining potency toward the hepatocyte lineage. Several recent studies have, however, shown minimal regeneration of the hepatocyte parenchyma by ductal-derived progenitors in vivo, in contrast to the robust contribution from hepatocytes themselves $(8,28-$ 30). Still, the clinical reality is that "ductular responses" are frequently observed in patients with chronic liver diseases $(31,32)$, where hepatocytes are mostly senescent (33). Conditional deletion of $M d m 2$ in up to $98 \%$ of hepatocytes, which causes them to senesce, activates a vigorous progenitor response that correlates with the full recovery of liver function in mice (27). Similar results have been observed in zebrafish livers after extensive hepatocyte loss (34). On the other hand, mature hepatocytes have been shown to undergo reversible ductular metaplasia in chronically damaged livers, regenerating up to $60 \%$ of their lost cell numbers, which suggests that part of the progenitor pool could originate from hepatocytes as an injury escape mechanism (35). Recently, using lineage tracing approaches, Raven and colleagues have unequivocally shown that ductal progenitors contribute to the regeneration of the hepatocyte lineage in murine livers with impaired hepatocyte proliferation caused by both $\mathrm{p} 21$ overexpression and loss of Itgb1 (encoding integrin $\beta_{1}$ ) (36).

Regardless of the cell-of-origin debate, what we can gather from these studies is an exceptional degree of epithelial plasticity in the regenerating liver (reviewed more exhaustively elsewhere, refs. 37-39). This is intimately linked to the source and extent of tissue damage and suggests an instructive role for the microenvironment. Indeed, the recovery from epithelialspecific injuries relies on auxiliary responses by nondamaged stromal cells that become activated in situ and get recruited from the bloodstream. Several paracrine signaling pathways, whose ligands are of stromal origin - WNT (40-44), hepatocyte growth factor $(\mathrm{HGF})(43,45,46)$, fibroblast growth factor (FGF) (47) - can directly stimulate epithelial cells to reenter cell cycle, dedifferentiate, and/or redifferentiate, and have been shown to be essential for regeneration (48). Wound healing is further characterized by the transient remodeling, de novo synthesis, and deposition of ECM, which releases latent cytokines (e.g., pro-HGF) (49) and ensures epithelial cell repositioning within the 3D histoarchitecture (50). A niche of fibrillar collagen and laminin invariably surrounds hepatic progenitor cells 
Table 1. Experimental animal models of liver fibrosis

\begin{tabular}{|c|c|c|c|c|}
\hline Models of liver fibrosis & Animal & Protocol/method & Onset of fibrosis & References \\
\hline \multicolumn{5}{|l|}{ Toxic/xenobiotics } \\
\hline Carbon tetrachloride $\left(\mathrm{CCl}_{4}\right)$ & Rats & s.c. or i.p. twice weekly, $0.2 \mathrm{ml} / 100 \mathrm{mg}$ body weight of $\mathrm{CCl}_{4}$ in oil (1:1 ratio) & $>4-6$ weeks & 168,169 \\
\hline \multirow[t]{3}{*}{ Dimethylnitrosamine (DMN) } & Rats & i.p., $10 \mathrm{mg} / \mathrm{kg}$ body weight, twice weekly & $>4$ weeks & 171,172 \\
\hline & Mice & i.p., $10 \mathrm{mg} / \mathrm{kg}$ body weight, thrice weekly & $>3$ weeks & 173 \\
\hline & Dogs & Orally twice weekly or intraportally once weekly & $>3-6$ weeks & 174,175 \\
\hline Thioacetamide (TAA) & & i.p., thrice weekly, $150-200 \mathrm{mg} / \mathrm{kg}$ body weight & $>6$ weeks & 178 \\
\hline $\begin{array}{l}\text { 3,5-Diethoxy-carbonyl-1,4- } \\
\text { dihydrocollidine (DDC) }\end{array}$ & Mice & Supplemented (0.1\%) in solid diet & $>4-8$ weeks & 179 \\
\hline \multirow[t]{2}{*}{ Ethanol } & Rats & Intragastric infusion of ethanol ( $25 \%-47 \%$ of calories) and high-fat diet & $>3$ months & 180 \\
\hline & Mice & Liquid diet with $5 \%$ ethanol for 10 days, then 1 dose $5 \mathrm{~g} / \mathrm{kg}$ body weight by gavage & Damage, no overt fibrosis & 181 \\
\hline $\begin{array}{l}\text { Choline-deficient, ethionine- } \\
\text { supplemented (CDE) diet }\end{array}$ & Rats & & $>10$ weeks & 184 \\
\hline \multirow{2}{*}{$\begin{array}{l}\text { Methionine- and choline-deficient } \\
\text { (MCD) diet }\end{array}$} & Mice & Methionine- and choline-deficient diet & $8-10$ weeks & 185 \\
\hline & Rats & & 10 weeks & 186,187 \\
\hline $\begin{array}{l}\text { Methionine- and choline-deficient, } \\
\text { ethionine-supplemented (MCDE) diet }\end{array}$ & Mice & $\begin{array}{l}\text { Methionine- and choline-deficient diet supplemented with } 0.15 \% \text { ethionine } \\
\text { in drinking water }\end{array}$ & 1-3 weeks & 188 \\
\hline \multicolumn{5}{|l|}{ Surgical } \\
\hline \multirow[t]{4}{*}{ Bile duct ligation } & Mice & Common extrahepatic bile duct is ligated & 3 weeks & 189 \\
\hline & Rats & & $>4$ weeks & 190 \\
\hline & Dogs & & $>4$ weeks & 191 \\
\hline & Monkeys & & $>8$ weeks & 192 \\
\hline$B c l-x \mid$ KO & Mice & KO of the antiapoptotic $B c l-x l$ conditional to hepatocytes (albumin-Cre) & $>5$ months postnatally & 199 \\
\hline Mdm2 KO & Mice & $\beta$-Naphthoflavone-inducible KO of Mdm2 conditional to hepatocytes (Ah-Cre) & $>3$ months & 27 \\
\hline \multicolumn{5}{|l|}{ Immunological } \\
\hline 2-OA-BSA $/ \alpha-C C$ & Mice & Immunization with 2-octynoic acid and BSA, then exposure to $\alpha$-galactosylceramide & $>4-12$ weeks & 200 \\
\hline
\end{tabular}

in the damaged liver, and loss of contact with specific matrix proteins may stimulate differentiation of the progenitor pool, as shown for laminin (51-53). The regeneration of the liver following acute injury thus requires a coordinated process of epithelial and stromal interactions that feed back onto one another until homeostasis is reestablished. The cessation of healing is albeit a process that is poorly understood. Hepatectomy studies point toward the existence of a "hepatostat" system that controls tissue size for optimal performance (4). In other organs, the Hippo pathway has been shown to limit tissue overgrowth by sensing cellular density and inactivating the proliferative, antiapoptotic program driven by Yes-associated protein (YAP) (54) and its paralog, the transcriptional coactivator with PDZ-binding motif
(TAZ), which may also negatively regulate WNT (55) and TGF- $\beta$ signaling (56), respectively. In the liver, defects in various components of the Hippo pathway lead to hepatomegaly and tumorigenesis due to uncontrolled proliferation of both hepatocytes and hepatic progenitors $(57,58)$. Moreover, YAP also drives HSC activation and matrix synthesis $(59,60)$, suggesting that Hippo signaling may simultaneously modulate regeneration and a maladaptive response leading to fibrosis (see below).

\section{Liver fibrosis and its cellular effectors}

Damage-induced matrix deposition is a transient phenomenon of the regenerative response, and successful healing entails its eventual removal $(61,62)$. Fibrosis occurs when ECM proteins 

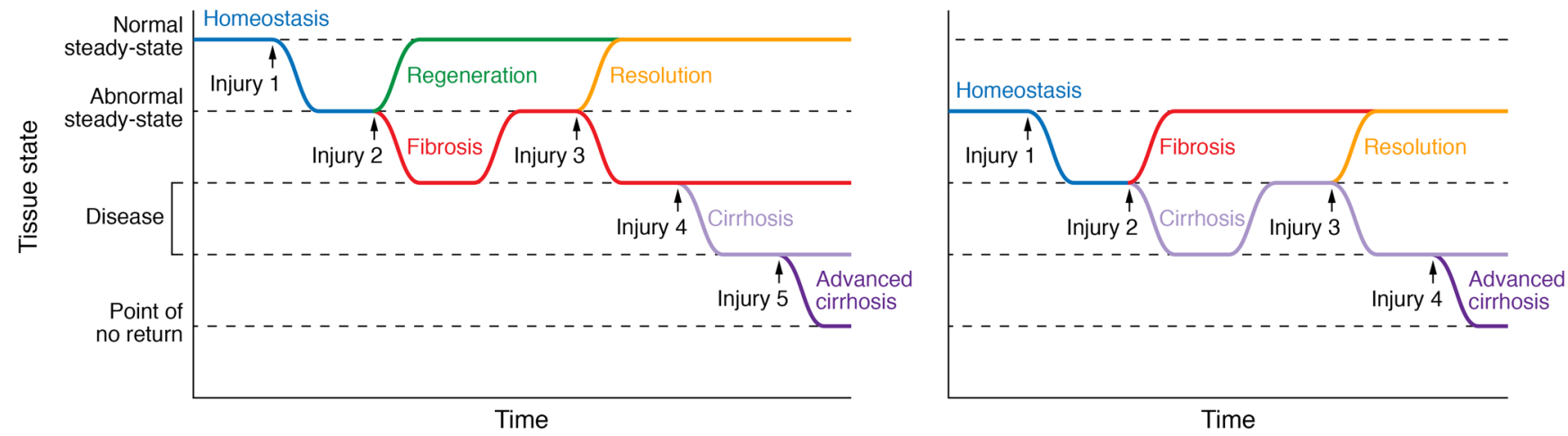

Figure 2. Periodicity of damage alters the ability of the tissue to return to homeostasis. (Left) In healthy individuals, a punctual tissue injury (injury 1) to the liver awakens a regenerative response (green curve) to reestablish homeostasis or steady-state. Repeated injuries (injuries $1+2$ ) hinder regeneration and make the system drift into a diseased state known as fibrosis (red curve). The tissue may recover from this as time progresses if no further damage is applied (resolution, injuries $1+2+$ time, yellow curve). Alternatively, fibrosis will be maintained in the face of new damage (injuries $1+2+3$, red curve). Additional injuries deteriorate the tissue until it reaches a cirrhotic $(1+2+3+4$, light purple curve) or advanced cirrhotic $(1+2+3+4+5$, dark purple curve) state. Recovery from this latter scenario is very unlikely. (Right) The tissue of predisposed individuals (e.g., aged) functions at an abnormal steady-state that makes them prone to develop fibrosis, thus accelerating disease progression and reaching a point of no recovery earlier.

accumulate in excessive amounts, leading to scarring that distorts the normal layout and stiffness of the tissue. Experimental models of hepatic fibrosis in rodents, dogs, and monkeys, whereby tissues are analyzed for collagen deposition (e.g., Sirius red staining), have been fundamental for studying the onset and pathogenesis of this disease (Table 1). As the injury becomes chronic, the oncefunctional hepatic parenchyma is overtaken by an acellular mesh of connective tissue - mostly collagen and elastin fibers - whose progressive cross-linking restrains access to degrading enzymes and makes scar resolution increasingly difficult (63).

The specialist producers of ECM in many tissues of the body are myofibroblasts: proliferative and migratory cells that express high levels of fibrillar collagens and tissue inhibitors of metalloproteinases (TIMPs) $(64,65)$. These cells are thought to have diverse origins, but they share a common process of transdifferentiation to acquire profibrotic traits in the context of damage (66). HSCs are microvasculature-associated pericytes and the best-studied precursors of myofibroblasts in the liver. These cells transition from quiescence to an active myofibroblast-like state following injury, and they are the dominant contributors to liver fibrosis, independent of its etiology (67). The ability of HSCs to respond to diverse types of damage may relate to their widespread placement in the liver architecture, which allows them to act swiftly at multiple sites of injury. In contrast, portal fibroblasts are found exclusively around the portal tract and predominantly drive fibrogenesis in biliary disease and cholangiocarcinomas (68). Bone marrow-recruited monocytes may also differentiate into ECM-producing "fibrocytes" as part of the inflammatory response, although transplantation studies suggest that their contribution to the development of hepatic fibrosis is minimal compared with that of tissue-resident mesenchymal cells $(69,70)$. The activation of "local" ECM producers may not be a universal mechanism in the body, however, considering that the fibrotic lung recruits a large amount of its collagen-producing cells from the bone marrow (71). In severely damaged livers, epithelial cells have also been proposed to feed the myofibroblast pool through an epithelial-to-mesenchymal transition (EMT) (72). The support for EMT has nonetheless been overreliant on the partial upregulation of mesenchymal markers in vitro, and a committed switch toward the myofibroblast lineage in vivo has not yet been formall proven $(73,74)$.

The transition from quiescent "cell X" (be it HSC, portal fibroblast, or monocyte) to active myofibroblast-like phenotype is a malleable process wherein the chronicity of the damage stimuli may generate a mixed spectrum of profibrotic cell signatures. While HSC-derived myofibroblasts have been reported to revert to quiescence readily $(75,76)$, myofibroblasts originating from portal fibroblasts are locked in a more mature/committed state and are unlikely to transition back (68). Understanding disease progression over the duration of injury as well as profibrotic cell heterogeneity is thus important when considering antifibrotic treatments.

\section{Cellular and molecular fluctuations balance regeneration and fibrosis}

Regeneration and fibrosis share a common cascade of injuryinduced events that bifurcates as a result of the chronicity of the damage (Figure 2). At the core of this cascade lie time-dependent multidirectional interactions between epithelial, mesenchymal, endothelial, and immune cells (Figure 3). Inflammation is one of the earliest processes following injury (1), preceding the actual repair of the lesion, and its mechanism is tightly linked to the type of damaging agent (i.e., underlying etiology). Commonly, dying cells or foreign antigens are recognized by tissue-resident or recruited leukocytes of the innate immune system, causing them to express proinflammatory agents (like TNF- $\alpha$ ) to further relay the "damage" signal (77). In that regard, in alcoholic liver disease and nonalcoholic steatohepatitis, overgrowth of LPS-containing gut bacteria induces liver-resident macrophages to produce reactive oxygen species and 


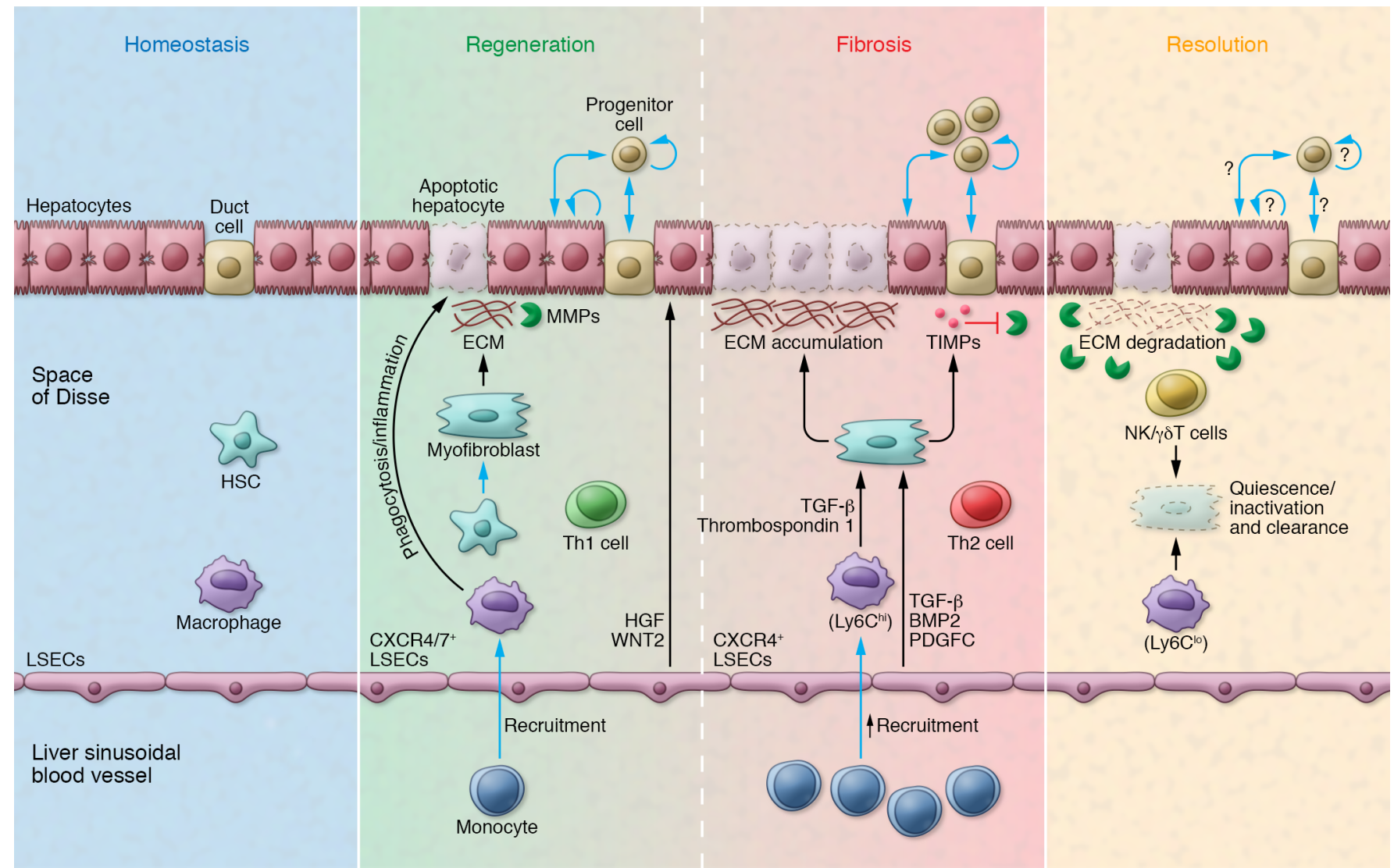

Figure 3. Distinct cellular landscapes characterize homeostasis, regeneration, fibrosis, and resolution in the liver. The homeostatic liver is characterized by rare cell proliferation and lack of de novo ECM deposition. During regeneration, epithelial replacement occurs predominantly via hepatocyte proliferation and, to a minor degree, through the activation of ductal progenitors. Resident (Kupffer) and bone marrow-recruited macrophages phagocytose the dead epithelium and launch an inflammatory cascade (e.g., TNF- $\alpha$, IL-6). CXCR7/CXCR4+ LSECs provide mitogenic signals (HCF, WNT2) that sustain hepatocyte proliferation. HSCs transdifferentiate into myofibroblasts that deposit ECM on the wound site, although this matrix can be degraded via MMPs. In fibrosis, the hepatocyte compartment is highly senescent and ductal progenitor expansion becomes predominant. Monocyte-derived Ly6C ${ }^{\text {hi }}$ macrophages (secreting TCF- $\beta$, thrombospondin 1) and CXCR4+ LSECs (secreting TCF- $\beta$, BMP2, and PDCFC) collectively enhance myofibroblast proliferation and survival. Myofibroblasts, in turn, secrete high levels of TIMPs, which inhibit MMPs and cause excessive matrix accumulation. A Th1- versus Th2-skewed immune system favors regeneration versus fibrosis, respectively. The resolution of fibrosis entails the return to quiescence/inactivation of myofibroblasts as well as their clearance by NK cells, $\gamma \delta$ T cells, and $\mathrm{Ly}_{6 \mathrm{C}^{10}}$ macrophages. High levels of MMPs contribute to matrix degradation. The mechanisms of epithelial replacement at this stage have not been fully elucidated.

TNF- $\alpha(78,79)$. On the other hand, viral hepatitis is different in that the hepatitis $\mathrm{C}$ virus (HCV) escapes immune surveillance and infects hepatocytes directly, causing oxidative stress as well as apoptosis $(80,81)$. Mesenchymal cells reinforce the inflammatory cascade by upregulating leukocyte-recruiting chemokines (82-85) and adhesion molecules (86), although they may also engage directly in classical innate immune roles like phagocytosis, antigen presentation, and $\mathrm{T}$ cell activation, as shown in isolated human HSCs (87). Acetaldehyde, the major metabolic product of alcohol, and HCV proteins directly stimulate the proinflammatory and fibrogenic profile of HSCs $(88,89)$. Studies in damaged skin (and after LPS or TNF- $\alpha$ stimulation in vitro) have shown that pericytes upregulate ICAM-1 and secrete macrophage migration inhibitory factor (MIF) to attract macrophages and neutrophils, which they later instruct with pattern recognition and motility programs (90). Macrophages can in turn activate quiescent HSCs into scar-forming myofibroblasts by secreting factors such as TGF- $\beta(91)$, PDGF $(92)$, galectin $3(93,94)$, and TNF- $\alpha$ (95). Indeed, activated myofibroblasts and macrophages spatially colocalize in areas of scar tissue. Depletion of macrophages with chemicals like gadolinium chloride and liposomal clodronate (96-98) or in ITGAM-DTR (also known as CD11B-DTR) transgenic (99) mice consistently dampens myofibroblast activation and tissue fibrosis in response to chronic injury. Yet macrophage populations are heterogeneous, and not all of them contribute equally to fibrosis (100). Liver-resident macrophages, known as Kupffer cells, ensure immunosurveillance of the tissue in homeostasis and contribute to the immediate response following injury partly through TNF and IL-6 $(101,102)$; however, these cells drop in numbers as inflammation progresses, while monocyte-derived macrophages increasingly colonize the tissue from the bloodstream (103-105). This latter population, described as $C D 11 \mathrm{~B}^{\text {hi }} \mathrm{F} 4 / 80^{\text {int }} \mathrm{Ly} 6 \mathrm{C}^{\mathrm{hi}}$, secretes high levels of TGF- $\beta$ and the TGF- $\beta$-activating protein thrombospondin 1 , thus supporting fibrinogenesis $(104,106)$.

Although seemingly profibrotic, macrophages have a far more complex role in the process of wound healing $(99,107)$. Mice exhibiting impaired infiltration of monocyte-derived 
macrophages (e.g., Ccr2 $2^{-/-}$mice) develop an attenuated form of hepatic fibrosis when persistently damaged, yet present defects to regress to homeostasis (108). Indeed, as part of a late-stage regenerative mechanism, recruited macrophages undergo a phenotypic switch from profibrotic $\left(\mathrm{CD} 11 \mathrm{~B}^{\mathrm{hi}} \mathrm{F} 4 / 80^{\mathrm{int}} \mathrm{Ly} 6 \mathrm{C}^{\text {hi }}\right)$ to scar-resolving $\left(\mathrm{CD} 11 \mathrm{~B}^{\mathrm{hi}} \mathrm{F} 4 / 80^{\text {int }} \mathrm{Ly} 6 \mathrm{C}^{\mathrm{lo}}\right)$, characterized by the increased expression of matrix metalloproteinases MMP13, MMP9, and MMP12 to clear away excess ECM, and upregulation of the TNF ligand superfamily member 10 (TNFSF10 or TRAIL), which can specifically trigger apoptosis in activated myofibroblasts due to their high expression of TRAIL receptors 1 and 2 (109). This phenotypic switch of macrophages, which is governed partially by phagocytosis (106), occurs in many other tissues, like muscle (110), skin (111), and lung (112), and hampering it may reinforce the pathogenic cycle of fibrosis. In wound healing, acute inflammation is also accompanied by a long-lasting adaptive immunity that is mounted by lymphocytes like T, B, and natural killer (NK) cells and is customized to the type of damage. This concept is interesting because it signifies that lifestyle, age, and disease history may pre-establish an important bias toward either regeneration or fibrosis (Figure 2). Th2 cells exacerbate fibrosis by secreting IL-4 and IL-13, which instigate macrophages to produce TGF- $\beta$ (113) and myofibroblasts to deposit ECM (114-116); on the other hand, Th1 cells prevent scar formation by producing IFN- $\gamma$ and IL-12, which counteract TGF- $\beta$ production $(117,118)$. As a result, mice with a Th2-dominant immune system (e.g., BALB/c mice) develop fibrosis more readily than Th1skewed mice (e.g., C57BL/6 mice) (119).

The liver's resident endothelium acts as a conduit for bloodborne proinflammatory agents that regulate early wound healing and actively secretes trophic factors for epithelial regrowth (43); yet somewhat paradoxically, angiogenesis is observed in progressive liver fibrosis (120). Recent work by Ding et al. puts in evidence how divergent signaling from LSECs can indeed balance regeneration and fibrosis. In acute injury, LSECs upregulate the chemokine receptor CXCR7, which cooperatively with CXCR4 signals through the DNA-binding protein inhibitor ID1 to produce pro-regenerative signals like WNT2 and HGF that drive hepatocyte expansion $(43,121)$. In chronic liver damage, constitutive FGF receptor 1 (FGFR1) signaling in LSECs decreases their ratio of CXCR7 to CXCR4 expression, overriding ID1 activation and instead stimulating the proliferation of HSCs via secretion of profibrotic cytokines like TGF- $\beta$, BMP2, and PDGFC. Endothelial cell-specific ablation of either Cxcr4 or Fgfrl or, conversely, upregulation of CXCR7 prevents fibrosis and restores the regenerative program (121).

The hepatic wound healing response is characterized by temporal fluctuations in gene expression, as if dictated by a molecular clock, and tampering with these dynamics may hinder the reacquisition of homeostasis. For instance, LSECs express angiopoietin 2 (ANG2) in a biphasic pattern following acute parenchymal damage: by sharply reducing their levels of ANG2 soon after injury, LSECs downregulate TGF- $\beta$, which in turn allows hepatocyte proliferation; recovered expression of ANG2 later boosts VEGFR2 levels in the LSECs in order to promote their own proliferation (122). BMP9, a TGF- $\beta$ family member secreted by HSCs, exhibits remarkably similar dynamics in vivo, whereby low levels initially promote hepatocyte expansion and higher ones are thought to stimulate HSC migration afterward (123). In fibrotic/cirrhotic livers, TGF- $\beta$ levels are notoriously elevated as a result of continuous activation of the profibrotic program $(124,125)$. We could then hypothesize that raising the baseline of TGF- $\beta$ may hinder the required drop in its concentration to induce hepatocyte proliferation, so that epithelial restitution (at least through the hepatocyte lineage; ref. 126) is overtaken by fibrosis.

Re-epithelization is the ultimate goal of the regenerative response. Be it through cell cycle reentry of mature cells or activation of facultative progenitors, this process relies on stromal signals (from LSECs, myofibroblasts, and/or macrophages) to fine-tune epithelial cell-fate choices according to local demand $(48,127)$. It is enticing to suggest that the expanding epithelium may concomitantly modulate stromal cell behavior in a positivefeedback loop to ensure appropriate regeneration, or, conversely, fibrosis when dysregulated. In line with that, transplantation of hepatocytes in healthy livers leads to the expansion of activated smooth muscle actin-positive HSCs, while HSC depletion diminishes hepatocyte cell engraftment (128). Similarly, exposure to free fatty acids induces HSC activation and collagen synthesis only in the presence of hepatocytes, at least in an in vitro model of nonalcoholic fatty liver disease (129). Although live hepatocytes do signal to their surrounding stroma, hepatocyte death prevails in chronic liver injuries and is typically recognized by professional phagocytes like Kupffer cells. Phagocytosis activates the proinflammatory program of macrophages (130) but also induces them to secrete WNT to specify hepatocyte differentiation of ductal progenitors (40). Myofibroblasts have similarly been observed to engulf hepatocyte-derived apoptotic bodies, which enhances their survival and production of matrix (131). In addition, the severity of liver fibrosis in many human pathologies - including chronic hepatitis $\mathrm{C}$ and alcoholic and nonalcoholic steatohepatitis - correlates closely with the amount of ductular expansion (132-134). Although ECM deposition chronologically precedes ductular proliferation, as shown in a choline-deficient, ethionine-supplemented (CDE) model of liver damage (135), activated ductal progenitors may reinforce pathogenesis by virtue of their expression of profibrotic mitogens/cytokines like PDGF (136), TGF- $\beta$ (137), insulin-like growth factor (IGF) (138), and monocyte chemoattractant protein-1 (MCP-1) (139). Prosurvival factors like IGF act on the biliary epithelium itself through autocrine signaling, leading some to hypothesize that "selfish" biliary maintenance unintentionally feeds the fibrotic response (140). Ductal cells may also sustain fibrosis indirectly by regulating the inflammatory cell milieu. Ductal cell-derived lymphotoxin- $\beta$ is profibrotic, not through direct HSC activation but instead through NF- $\mathrm{BB}-$ mediated induction of the leukocyte-recruiting molecules ICAM- 1 and CCL5 in these cells (141). Other chemokines reported within the ductular repertoire include IL-6 (142) and IL-8 (143), albeit their expression requires priming by proinflammatory factors like IFN- $\gamma$.

\section{Reversal of fibrosis: potential for therapy}

For many years tissue fibrosis was considered to be a degenerative disease with no possibility of regression. A seminal study by Okazaki and Maruyama in 1974 was the first to show collagenase activity in fibrotic livers, hinting at the feasibility of 
disease resolution under certain contexts (144). Since then, the liver has provided exceptional evidence of the plasticity of this process, where even advanced fibrotic tissues are capable of reacquiring homeostatic traits (refs. 6, 145, and Figures 2 and $3)$. The most effective therapy for treating liver fibrosis to date is still to remove the damaging agent. Case in point are clinical cases of cirrhotic livers arising from chronic HCV infection, which achieve remarkable histological regression following antiviral treatment $(146,147)$. From this we can infer that the liver does contain built-in mechanisms for scar resolution, but these become smothered or inactivated in the face of relentless damage. The removal of profibrotic inputs, or, conversely, the strengthening of antifibrotic ones, should then stimulate scar resolution to at least some extent.

At the ground level, the battle is enzymatic: matrix-degrading enzymes must overcome the inhibitory action of TIMPs for a scar to be broken down. Overexpression of enzymes like MMP1 and MMP8 through adenoviral delivery has proven to ameliorate established fibrosis in rat livers $(148,149)$. Compounding the problem is the chronic persistence of myofibroblasts, which continuously pump TIMPs into the microenvironment, owing to prosurvival signaling via TGF- $\beta$ and the TNF- $\alpha / N F-\kappa B$ axis (150). A single injection of the fungal toxin gliotoxin following chronic carbon tetrachloride $\left(\mathrm{CCl}_{4}\right)$ damage promotes myofibroblast apoptosis through NF- $\kappa \mathrm{B}$ inhibition in these cells and significantly resolves hepatic fibrosis in a matter of days (151). Whether this is solely due to myofibroblast death is still to be determined, given that NF- $\kappa \mathrm{B}$ is also critical for the transcription of multiple immune cell-derived cytokines like IL-1 (152), whose direct blockade has shown potential for reducing liver fibrosis (153).

Clearance of myofibroblasts by phenotypically apt immune cells can prove of great benefit to resolve scarring in chronically damaged tissues. Indeed, fibrosis regression in the liver is accompanied by increased numbers of dendritic cells (DCs) (154), NK cells (155), and macrophages (106) in the tissue parenchyma. While DCs directly target ECM degradation through MMP9 secretion (154), NK cells target activated and senescent myofibroblasts for apoptosis through IFN- $\gamma$-induced NKG2-D type II integral membrane protein (NKG2D), TRAIL, and FasL $(156,157)$. T cells expressing the $\gamma \delta \mathrm{T}$ cell receptor can also induce myofibroblast apoptosis via the Fas/FasL axis and thereby limit hepatic fibrosis (158). Tissue-restorative

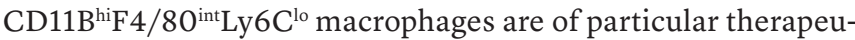
tic interest because of their double-hit strategy: high secretion of MMPs and induction of myofibroblast apoptosis. A promising antifibrotic therapy would then be to increase the effective number of $\mathrm{CD}_{11} \mathrm{~B}^{\mathrm{hi}} \mathrm{F} 4 / 80^{\mathrm{int}} \mathrm{Ly} 6 \mathrm{C}^{\mathrm{lo}}$ macrophages within the tissue through autologous transplants. In conjunction, blocking the influx of profibrotic $\mathrm{CD} 11 \mathrm{~B}^{\mathrm{hi}} \mathrm{F} 4 / 80^{\text {int }} \mathrm{Ly} 6 \mathrm{C}^{\text {hi }}$ macrophages (accomplished by targeting of the CCL2/CCR2 axis, which attracts monocytes to the liver; refs. 108, 159) could further tilt the balance toward regeneration.

Profibrotic cells can also be inactivated or induced to senesce, as opposed to targeted for cell death. There is now growing evidence that myofibroblasts can revert to their original quiescent-like state, albeit the cell of origin may affect the plasticity of a given myofibroblast population (see above). Moreover, reversal to quiescence is never $100 \%$ successful; deactivated cells do not fully suppress their profibrotic gene signature and instead remain in a "primed" state that is capable of aggravating fibrosis upon further stimuli (75, 76). Senescence of a myofibroblast cell dampens its ability to synthesize matrix and profibrotic cytokines, yet in contrast to deactivation, this phenotype is associated with cell cycle exit and confers susceptibility to immune cell-mediated killing, particularly by NK cells (160). Replicative exhaustion, overstimulation, and oxidative stress are some of the mechanisms suggested to induce HSC senescence. In particular, one study has shown that signaling through the IL-22/STAT3 axis promotes HSC senescence, and accordingly, IL-22 treatment ameliorates liver fibrosis in vivo (161).

The disentangling of fibrosis requires multitargeted efforts because of the redundancy of the pathways that sustain it, mirroring the complexity of anticancer therapies. What this means in clinical terms is that "precision medicine" based on targeted single therapeutics (e.g., a blocking antibody against PDGFB; ref. 162) is unlikely to have robust and durable effects. Cellular therapies are attractive because they signify a continuous/responsive supply of diverse antifibrotic effectors. Interestingly, Lu and colleagues have shown that transplanting in vitro-expanded $\mathrm{EpCAM}^{+} \mathrm{CD} 24^{+} \mathrm{CD} 133^{+}$ductal progenitors in damaged livers not only repopulates hepatocellular parenchyma but also reduces liver scarring, the latter through mechanisms currently unknown (27). Still, incorporating the right cell in the "wrong" niche can be futile; thus, there is an increasing need to accurately assess and model disease progression beyond the current invasive method of tissue biopsy. The clinical efforts to modulate regeneration and fibrosis are, after all, a game of timing: an antifibrotic therapy aimed at quenching ECM deposition or inflammation in the very early stages of fibrosis could paradoxically impair hepatic regeneration. Similarly, engrafting ductal progenitors in advanced fibrotic livers could potentiate myofibroblast activation.

\section{Future perspectives and conclusion}

Much of what we understand about fibrosis - its pathology and potential treatments - has been gathered from in vivo animal models of chronic tissue damage. Advanced liver fibrosis is, however, much less reversible in humans because of the decades, instead of weeks, of tissue damage and collagen cross-linking (163). Even after accounting for the variable of time, we cannot rule out species-specific differences in regeneration that may hinder our ability to treat patients. Thus, it may be time for the field to develop innovative human models of liver fibrosis.

Historically, in vitro studies of fibrosis have relied on "stripped-down" strategies involving short-lived primary cells and/or immortalized hepatic lines from healthy and diseased livers. Although simplistic, this has led to critical discoveries in the field, such as the molecular mechanism behind myofibroblast transdifferentiation (a process that occurs spontaneously when HSCs are cultured on plastic) (164). Human adult-derived hepatic progenitors can now be expanded in vitro as highly proliferative, yet genomically stable, 3D organoid structures that incorporate epithelial heterogeneity from the bile duct and hepatocyte lineages (26), proving of great biomedical potential for hepatic disease modeling (165). Still, the lack of stromal cells in these organoids restricts their ability to model complex diseases like fibrosis, 
whose pathogenesis involves matrix-depositing, inflammatory, and endothelial cells. Takebe and colleagues have pioneered the idea of a truly organotypic human liver culture, albeit embryonic, by coculturing hepatic progenitors derived from human induced pluripotent stem cells with mesenchyme and endothelium (using human mesenchymal cells and HUVECs) in order to recapitulate key cell-cell interactions that lead to liver-bud formation in the embryo (166). Adult hepatic cultures will likely be challenged by the higher diversification of stromal cells in the tissue - HSCs, portal fibroblasts, LSECs, Kupffer cells, and recruited inflammatory cells - as well as the time-dependent changes that occur following acute versus chronic damage. Multiscale mathematical models, as have been constructed with mouse liver data (167), may be further required to integrate and predict the evolution of cell-cell interactions in space and time. In vitro and in silico approaches like these will never recapitulate the entirety of the fibrotic response at the whole-organism level, but may provide crucial mechanistic information about the complex cellular and molecular crosstalk that underlies human pathology, especially at the early stages of the fibrotic response.

In conclusion, injury of the hepatic tissue activates a spatiotemporally controlled reaction involving inflammatory cell recruitment, matrix deposition, and epithelial cell replacement. Although the liver's plasticity accommodates for a multitude of damaging insults, tissue degeneration and scarring often develop over time. Understanding the mechanisms that balance tissue regeneration and fibrosis is thus essential to identify new avenues of therapeutic intervention as well as to predict disease progres- sion. The studies reviewed here have highlighted the time-dependent duality (pro-regenerative versus profibrotic) of the cells and molecules that drive wound healing. Be it by deactivation or clearance, regenerative pathways must be terminated; otherwise they become appropriated for fibrosis. In chronically damaged livers, the vicious cycle of cell death, inflammation, and excessive ECM deposition overrides epithelial restoration. Yet even cirrhotic livers may partially regress to homeostasis if antifibrotic inputs outbalance profibrotic ones, proving once again the malleability of the liver tissue. Focus should, then, be placed on developing multitargeted therapies that cripple the self-maintenance of fibrosis. Lastly, the field would benefit from complementary organotypic cultures and in silico models to shed light on the dynamics that govern regeneration and fibrosis in humans.

\section{Acknowledgments}

LCE is jointly funded by a Wellcome Trust Four-Year PhD Studentship with the Stem Cell Biology and Medicine Programme and a Wellcome Cambridge Trust Scholarship. $\mathrm{MH}$ is a Wellcome Trust Sir Henry Dale Fellow and is jointly funded by the Wellcome Trust and the Royal Society (104151/Z/14/Z). This work is partially funded by an H2020 grant awarded to MH (LSMF4LIFE).

Address correspondence to: Meritxell Huch, Wellcome Trust/ Cancer Research UK Gurdon Institute, Henry Wellcome Building of Cancer and Developmental Biology, Tennis Court Road, Cambridge CB2 1QN, United Kingdom. Phone: 44.0.1223.334088; Email:m.huch@gurdon.cam.ac.uk.
1. Gurtner G, Werner S, Barrandon Y, Longaker $\mathrm{M}$. Wound repair and regeneration. Nature. 2008;453(7193):314-321.

2. Sánchez Alvarado A. Regeneration in the metazoans: why does it happen? Bioessays. 2000;22(6):578-590.

3. Timchenko NA. Aging and liver regeneration. Trends Endocrinol Metab. 2009;20(4):171-176.

4. Michalopoulos GK. Liver regeneration. J Cell Physiol. 2007;213(2):286-300.

5 . Taub R. Liver regeneration: from myth to mechanism. Nat Rev Mol Cell Biol. 2004;5(10):836-847.

6. Bataller R, Brenner D. Liver fibrosis. JClin Invest. 2005;115(2):209-218.

7. Wang B, Zhao L, Fish M, Logan CY, Nusse R. Self-renewing diploid Axin2(+) cells fuel homeostatic renewal of the liver. Nature. 2015;524(7564):180-185.

8. Tarlow BD, Finegold MJ, Grompe M. Clonal tracing of Sox $9^{+}$liver progenitors in mouse oval cell injury. Hepatology. 2014;60(1):278-289.

9. MacDonald RA. "Lifespan" of liver cells. Autoradio-graphic study using tritiated thymidine in normal, cirrhotic, and partially hepatectomized rats. Arch Intern Med. 1961;107:335-343.

10. Michalopoulos GK, DeFrances MC. Liver regeneration. Science. 1997;276(5309):60-66.

11. Lim YS, Kim WR. The global impact of hepatic fibrosis and end-stage liver disease. Clin Liver Dis. 2008;12(4):733-746.

12. Asrani SK, Larson JJ, Yawn B, Therneau TM, Kim WR. Underestimation of liver-related mortality in the United States. Gastroenterology. 2013;145(2):375-82.e1.

13. Fancy SP, Chan JR, Baranzini SE, Franklin RJ, Rowitch DH. Myelin regeneration: a recapitulation of development? Annu Rev Neurosci. 2011;34:21-43.

14. Miyajima A, Tanaka M, Itoh T. Stem/progenitor cells in liver development, homeostasis, regeneration, and reprogramming. Cell Stem Cell. 2014;14(5):561-574.

15. Rock JR, Hogan BL. Epithelial progenitor cells in lung development, maintenance, repair, and disease. Annu Rev Cell Dev Biol. 2011;27:493-512.

16. Shi X, Garry DJ. Muscle stem cells in development, regeneration, and disease. Genes Dev. 2006;20(13):1692-1708.

17. Clevers H, Loh KM, Nusse R. Stem cell signaling. An integral program for tissue renewal and regeneration: Wnt signaling and stem cell control. Science. 2014;346(6205):1248012.

18. Grisham JW, Porta EA. Origin and fate of proliferated hepatic ductal cells in the rat: electron microscopic and autoradiographic studies. Exp Mol Pathol. 1964;3:242-261.

19. Evarts RP, Nagy P, Nakatsukasa H, Marsden E, Thorgeirsson SS. In vivo differentiation of rat liver oval cells into hepatocytes. Cancer Res. 1989;49(6):1541-1547.

20. Sell S. Is there a liver stem cell? Cancer Res. 1990;50(13):3811-3815.

21. Furuyama K, et al. Continuous cell supply from a Sox9-expressing progenitor zone in adult liver, exocrine pancreas and intestine. Nat Genet. 2011;43(1):34-41.
22. Español-Suñer R, et al. Liver progenitor cells yield functional hepatocytes in response to chronic liver injury in mice. Gastroenterology. 2012;143(6):1564-1575.e7.

23. Huch M, et al. In vitro expansion of single Lgr5 $5^{+}$ liver stem cells induced by Wnt-driven regeneration. Nature. 2013;494(7436):247-250.

24. Dorrell C, et al. Prospective isolation of a bipotential clonogenic liver progenitor cell in adult mice. Genes Dev. 2011;25(11):1193-1203.

25. Shin S, et al. Foxl1-Cre-marked adult hepatic progenitors have clonogenic and bilineage differentiation potential. Genes Dev. 2011;25(11):1185-1192.

26. Huch M, et al. Long-term culture of genomestable bipotent stem cells from adult human liver. Cell. 2015;160(1-2):299-312.

27. Lu WY, et al. Hepatic progenitor cells of biliary origin with liver repopulation capacity. Nat Cell Biol. 2015;17(8):971-983.

28. Schaub JR, Malato Y, Gormond C, Willenbring H. Evidence against a stem cell origin of new hepatocytes in a common mouse model of chronic liver injury. Cell Rep. 2014;8(4):933-939.

29. Yanger K, et al. Adult hepatocytes are generated by self-duplication rather than stem cell differentiation. Cell Stem Cell. 2014;15(3):340-349.

30. Font-Burgada J, et al. Hybrid periportal hepatocytes regenerate the injured liver without giving rise to cancer. Cell. 2015;162(4):766-779.

31. Roskams T, Desmet V. Ductular reaction and its diagnostic significance. Semin Diagn Pathol. 1998;15(4):259-269.

32. Lowes KN, Brennan BA, Yeoh GC, Olynyk JK. 
Oval cell numbers in human chronic liver diseases are directly related to disease severity. $\mathrm{Am} \mathrm{J}$ Pathol.1999;154(2):537-541.

33. Wiemann SU, et al. Hepatocyte telomere shortening and senescence are general markers of human liver cirrhosis. FASEB J. 2002;16(9):935-942.

34. Choi TY, Ninov N, Stainier DY, Shin D. Extensive conversion of hepatic biliary epithelial cells to hepatocytes after near total loss of hepatocytes in zebrafish. Gastroenterology. 2014;146(3):776-788.

35. Tarlow BD, et al. Bipotential adult liver progenitors are derived from chronically injured mature hepatocytes. Cell Stem Cell. 2014;15(5):605-618.

36. Raven A, et al. Cholangiocytes act as facultative liver stem cells during impaired hepatocyte regeneration. Nature. 2017;547(7663):350-354.

37. Hindley CJ, Mastrogiovanni G, Huch M. The plastic liver: differentiated cells, stem cells, every cell? J Clin Invest. 2014;124(12):5099-5102.

38. Aloia L, Mckie MA, Huch M. Cellular plasticity in the adult liver and stomach. J Physiol. 2016;594(17):4815-4825.

39. Huch M, Dollé L. The plastic cellular states of liver cells: are EpCAM and Lgr5 fit for purpose? Hepatology. 2016;64(2):652-662.

40. Boulter L, et al. Macrophage-derived Wnt opposes Notch signaling to specify hepatic progenitor cell fate in chronic liver disease. Nat Med. 2012;18(4):572-579.

41. Monga SP, Pediaditakis P, Mule K, Stolz DB, Michalopoulos GK. Changes in WNT/beta-catenin pathway during regulated growth in rat liver regeneration. Hepatology. 2001;33(5):1098-1109.

42. Apte $\mathrm{U}$, et al. $\beta$-Catenin activation promotes liver regeneration after acetaminophen-induced injury. Am J Pathol. 2009;175(3):1056-1065.

43. Ding BS, et al. Inductive angiocrine signals from sinusoidal endothelium are required for liver regeneration. Nature. 2010;468(7321):310-315.

44. Rocha AS, et al. The angiocrine factor Rspondin 3 is a key determinant of liver zonation. Cell Rep. 2015;13(9):1757-1764.

45. Matsumoto K, Nakamura T. Hepatocyte growth factor: molecular structure and implications for a central role in liver regeneration. J Gastroenterol Hepatol. 1991;6(5):509-519.

46. Chen L, et al. HSCs play a distinct role in different phases of oval cell-mediated liver regeneration. Cell Biochem Funct. 2012;30(7):588-596.

47. Takase HM, et al. FGF7 is a functional niche signal required for stimulation of adult liver progenitor cells that support liver regeneration. Genes Dev. 2013;27(2):169-181.

48. Boulter L, Lu WY, Forbes SJ. Differentiation of progenitors in the liver: a matter of local choice. JClin Invest. 2013;123(5):1867-1873.

49. Mohammed FF, Khokha R. Thinking outside the cell: proteases regulate hepatocyte division. Trends Cell Biol. 2005;15(10):555-563.

50. Friedl P, Gilmour D. Collective cell migration in morphogenesis, regeneration and cancer. Nat Rev Mol Cell Biol. 2009;10(7):445-457.

51. Lorenzini S, et al. Characterisation of a stereotypical cellular and extracellular adult liver progenitor cell niche in rodents and diseased human liver. Gut. 2010;59(5):645-654.

52. Paku S, Nagy P, Kopper L, Thorgeirsson SS. 2-Acetylaminofluorene dose-dependent differ- entiation of rat oval cells into hepatocytes: confocal and electron microscopic studies. Hepatology. 2004;39(5):1353-1361.

53. Williams MJ, Clouston AD, Forbes SJ. Links between hepatic fibrosis, ductular reaction, and progenitor cell expansion. Gastroenterology. 2014;146(2):349-356.

54. Zhao B, Tumaneng K, Guan KL. The Hippo pathway in organ size control, tissue regeneration and stem cell self-renewal. Nat Cell Biol. 2011;13(8):877-883.

55. Heallen T, et al. Hippo pathway inhibits Wnt signaling to restrain cardiomyocyte proliferation and heart size. Science. 2011;332(6028):458-461.

56 . Varelas X, et al. TAZ controls Smad nucleocytoplasmic shuttling and regulates human embryonic stem-cell self-renewal. Nat Cell Biol. 2008;10(7):837-848.

57. Lee KP, et al. The Hippo-Salvador pathway restrains hepatic oval cell proliferation, liver size, and liver tumorigenesis. Proc Natl Acad Sci U S A. 2010;107(18):8248-8253.

58. Lu L, et al. Hippo signaling is a potent in vivo growth and tumor suppressor pathway in the mammalian liver. Proc Natl Acad Sci U S A. 2010;107(4):1437-1442.

59. Liu F, et al. Mechanosignaling through YAP and TAZ drives fibroblast activation and fibrosis. Am JPhysiol Lung Cell Mol Physiol. 2015;308(4):L344-L357.

60. Mannaerts I, et al. The Hippo pathway effector YAP controls mouse hepatic stellate cell activation. J Hepatol. 2015;63(3):679-688.

61. Issa R, et al. Mutation in collagen-1 that confers resistance to the action of collagenase results in failure of recovery from CCl4-induced liver fibrosis, persistence of activated hepatic stellate cells, and diminished hepatocyte regeneration. FASEB J. 2003;17(1):47-49.

62. Kallis YN, et al. Remodelling of extracellular matrix is a requirement for the hepatic progenitor cell response. Gut. 2011;60(4):525-533.

63. Ramachandran P, Iredale JP. Liver fibrosis: a bidirectional model of fibrogenesis and resolution. QJM. 2012;105(9):813-817.

64. Iredale JP, Murphy G, Hembry RM, Friedman SL, Arthur MJ. Human hepatic lipocytes synthesize tissue inhibitor of metalloproteinases-1. Implications for regulation of matrix degradation in liver. J Clin Invest. 1992;90(1):282-287.

65. Tomasek JJ, Gabbiani G, Hinz B, Chaponnier C, Brown RA. Myofibroblasts and mechano-regulation of connective tissue remodelling. Nat Rev Mol Cell Biol. 2002;3(5):349-363.

66. Hinz B, Phan SH, Thannickal VJ, Galli A, Bochaton-Piallat M-L, Gabbiani G. The myofibroblast: one function, multiple origins. Am J Pathol. 2007;170(6):1807-1816

67. Mederacke I, et al. Fate tracing reveals hepatic stellate cells as dominant contributors to liver fibrosis independent of its aetiology. Nat Commun. 2013;4:2823.

68. Lepreux S, Desmoulière A. Human liver myofibroblasts during development and diseases with a focus on portal (myo)fibroblasts. Front Physiol. 2015;6:173.

69. Kisseleva T, et al. Bone marrow-derived fibrocytes participate in pathogenesis of liver fibrosis. JHepatol. 2006;45(3):429-438.
70. Brenner DA, Kisseleva T, Scholten D, et al. Origin of myofibroblasts in liver fibrosis. Fibrogenesis Tissue Repair. 2012;5(suppl 1):S17.

71. Hashimoto N, Jin H, Liu T, Chensue SW, Phan SH. Bone marrow-derived progenitor cells in pulmonary fibrosis. J Clin Invest. 2004;113(2):243-252.

72. Choi SS, Diehl AM. Epithelial-to-mesenchymal transitions in the liver. Hepatology. 2009;50(6):2007-2013.

73. Taura K, et al. Hepatocytes do not undergo epithelial-mesenchymal transition in liver fibrosis in mice. Hepatology. 2010;51(3):1027-1036.

74. Scholten D, et al. Genetic labeling does not detect epithelial-to-mesenchymal transition of cholangiocytes in liver fibrosis in mice. Gastroenterology. 2010;139(3):987-998.

75. Kisseleva T, et al. Myofibroblasts revert to an inactive phenotype during regression of liver fibrosis. Proc Natl Acad Sci U S A. 2012;109(24):9448-9453.

76. Troeger JS, et al. Deactivation of hepatic stellate cells during liver fibrosis resolution in mice. Gastroenterology. 2012;143(4):1073-1083.e22.

77. Canbay A, et al. Kupffer cell engulfment of apoptotic bodies stimulates death ligand and cytokine expression. Hepatology. 2003;38(5):1188-1198.

78. Hines IN, Wheeler MD. Recent advances in alcoholic liver disease III. Role of the innate immune response in alcoholic hepatitis. Am J Physiol Gastrointest Liver Physiol. 2004;287(2):G310-G314.

79. Tilg H, Moschen AR. Evolution of inflammation in nonalcoholic fatty liver disease: the multiple parallel hits hypothesis. Hepatology. 2010;52(5):1836-1846.

80. Schuppan D, Krebs A, Bauer M, Hahn EG. Hepatitis C and liver fibrosis. Cell Death Differ. 2003;10(suppl 1):S59-S67.

81. Loguercio C, Federico A. Oxidative stress in viral and alcoholic hepatitis. Free Radic Biol Med. 2003;34(1):1-10.

82. Marra F, Valente AJ, Pinzani M, Abboud HE. Cultured human liver fat-storing cells produce monocyte chemotactic protein-1. Regulation by proinflammatory cytokines. JClin Invest. 1993;92(4):1674-1680.

83. Maher JJ, Lozier JS, Scott MK. Rat hepatic stellate cells produce cytokine-induced neutrophil chemoattractant in culture and in vivo. Am J Physiol. 1998;275(4 pt 1):G847-G853.

84. Sprenger H, Kaufmann A, Garn H, Lahme B, Gemsa D, Gressner AM. Induction of neutrophilattracting chemokines in transforming rat hepatic stellate cells. Gastroenterology. 1997;113(1):277-285

85. Holt AP, Haughton EL, Lalor PF, Filer A, Buckley $\mathrm{CD}$, Adams DH. Liver myofibroblasts regulate infiltration and positioning of lymphocytes in human liver. Gastroenterology. 2009;136(2):705-714.

86. Knittel T, et al. Expression and regulation of cell adhesion molecules by hepatic stellate cells (HSC) of rat liver: involvement of HSC in recruitment of inflammatory cells during hepatic tissue repair. Am J Pathol. 1999;154(1):153-167.

87. Viñas $\mathrm{O}$, et al. Human hepatic stellate cells show features of antigen-presenting cells and stimulate lymphocyte proliferation. Hepatology. 2003;38(4):919-929.

88. Maher JJ, Zia S, Tzagarakis C. Acetaldehydeinduced stimulation of collagen synthesis and 
gene expression is dependent on conditions of cell culture: studies with rat lipocytes and fibroblasts. Alcohol Clin Exp Res. 1994;18(2):403-409.

89. Bataller R, Paik YH, Lindquist JN, Lemasters JJ, Brenner DA. Hepatitis $\mathrm{C}$ virus core and nonstructural proteins induce fibrogenic effects in hepatic stellate cells. Gastroenterology. 2004;126(2):529-540.

90. Stark K, et al. Capillary and arteriolar pericytes attract innate leukocytes exiting through venules and 'instruct' them with pattern-recognition and motility programs. Nat Immunol. 2013;14(1):41-51.

91. Matsuoka M, Tsukamoto H. Stimulation of hepatic lipocyte collagen production by Kupffer cellderived transforming growth factor beta: implication for a pathogenetic role in alcoholic liver fibrogenesis. Hepatology. 1990;11(4):599-605.

92. Friedman SL, Arthur MJ. Activation of cultured rat hepatic lipocytes by Kupffer cell conditioned medium. Direct enhancement of matrix synthesis and stimulation of cell proliferation via induction of platelet-derived growth factor receptors. JClin Invest. 1989;84(6):1780-1785.

93. Henderson NC, et al. Galectin-3 regulates myofibroblast activation and hepatic fibrosis. Proc Natl Acad Sci U S A. 2006;103(13):5060-5065.

94. Sato S, Hughes RC. Regulation of secretion and surface expression of Mac-2, a galactosidebinding protein of macrophages. J Biol Chem. 1994;269(6):4424-4430.

95. Kamimura S, Tsukamoto H. Cytokine gene expression by Kupffer cells in experimental alcoholic liver disease. Hepatology. 1995;22(4 pt 1):1304-1309.

96. Ide M, Kuwamura M, Kotani T, Sawamoto $\mathrm{O}$, Yamate J. Effects of gadolinium chloride $(\mathrm{GdCl}(3))$ on the appearance of macrophage populations and fibrogenesis in thioacetamideinduced rat hepatic lesions. J Comp Pathol. 2005;133(2-3):92-102.

97. Sunami $Y$, et al. Hepatic activation of IKK/NFאB signaling induces liver fibrosis via macrophagemediated chronic inflammation. Hepatology. 2012;56(3):1117-1128.

98. Pradere JP, et al. Hepatic macrophages but not dendritic cells contribute to liver fibrosis by promoting the survival of activated hepatic stellate cells in mice. Hepatology. 2013;58(4):1461-1473.

99. Duffield JS, et al. Selective depletion of macrophages reveals distinct, opposing roles during liver injury and repair. J Clin Invest. 2005;115(1):56-65.

100. Tacke F, Zimmermann HW. Macrophage heterogeneity in liver injury and fibrosis. J Hepatol. 2014;60(5):1090-1096.

101.Selzner N, Selzner M, Odermatt B, Tian Y, Van Rooijen N, Clavien PA. ICAM-1 triggers liver regeneration through leukocyte recruitment and Kupffer cell-dependent release of TNF- $\alpha / \mathrm{IL}-6$ in mice. Gastroenterology. 2003;124(3):692-700.

102. Meijer C, et al. Kupffer cell depletion by CI2MDP-liposomes alters hepatic cytokine expression and delays liver regeneration after partial hepatectomy. Liver. 2000;20(1):66-77.

103. Marra F, et al. Expression of monocyte chemotactic protein-1 precedes monocyte recruitment in a rat model of acute liver injury, and is modulated by vitamin E. J Investig Med. 1999;47(1):66-75.

104.Karlmark KR, et al. Hepatic recruitment of the inflammatory Gr1+ monocyte subset upon liver injury promotes hepatic fibrosis. Hepatology. 2009;50(1):261-274.

105. Dambach DM, Watson LM, Gray KR, Durham SK, Laskin DL. Role of CCR2 in macrophage migration into the liver during acetaminopheninduced hepatotoxicity in the mouse. Hepatology. 2002;35(5):1093-1103.

106. Ramachandran P, et al. Differential Ly-6C expression identifies the recruited macrophage phenotype, which orchestrates the regression of murine liver fibrosis. Proc Natl Acad Sci U S A. 2012;109(46):E3186-E3195.

107. Fallowfield JA, et al. Scar-associated macrophages are a major source of hepatic matrix metalloproteinase-13 and facilitate the resolution of murine hepatic fibrosis. J Immunol. 2007;178(8):5288-5295.

108. Mitchell C, et al. Dual role of CCR2 in the constitution and the resolution of liver fibrosis in mice. Am J Pathol. 2009;174(5):1766-1775.

109. Taimr P, Higuchi H, Kocova E, Rippe RA, Friedman S, Gores GJ. Activated stellate cells express the TRAIL receptor-2/death receptor- 5 and undergo TRAIL-mediated apoptosis. Hepatology. 2003;37(1):87-95.

110. Arnold L, et al. Inflammatory monocytes recruited after skeletal muscle injury switch into antiinflammatory macrophages to support myogenesis. JExp Med. 2007;204(5):1057-1069.

111. Rodero MP, Hodgson SS, Hollier B, Combadiere C, Khosrotehrani K. Reduced Il17a expression distinguishes a Ly6c(lo)MHCII(hi) macrophage population promoting wound healing. J Invest Dermatol. 2013;133(3):783-792.

112. Gibbons MA, et al. Ly6Chi monocytes direct alternatively activated profibrotic macrophage regulation of lung fibrosis. Am J Respir Crit Care Med. 2011;184(5):569-581.

113. Fichtner-Feigl S, Strober W, Kawakami K, Puri RK, Kitani A. IL-13 signaling through the IL- $13 \alpha 2$ receptor is involved in induction of TGF- $\beta 1$ production and fibrosis. Nat Med. 2006;12(1):99-106.

114. Doucet C, Brouty-Boyé D, Pottin-Clémenceau C, Canonica GW, Jasmin C, Azzarone B. Interleukin (IL) 4 and IL-13 act on human lung fibroblasts. Implication in asthma. JClin Invest. 1998;101(10):2129-2139.

115. Tiggelman AM, Boers W, Linthorst C, Sala M, Chamuleau RA. Collagen synthesis by human liver (myo)fibroblasts in culture: evidence for a regulatory role of IL- $1 \beta, \mathrm{IL}-4$, TGF- $\beta$, and IFN- $\gamma$. J Hepatol. 1995;23(3):307-317.

116. Chiaramonte MG, Donaldson DD, Cheever AW, Wynn TA. An IL-13 inhibitor blocks the development of hepatic fibrosis during a T-helper type 2-dominated inflammatory response. J Clin Invest. 1999;104(6):777-785.

117. Wynn TA, et al. An IL-12-based vaccination method for preventing fibrosis induced by schistosome infection. Nature. 1995;376(6541):594-596.

118. Marth T, Strober W, Seder RA, Kelsall BL. Regulation of transforming growth factor-beta production by interleukin-12. Eur J Immunol. 1997;27(5):1213-1220.

119. Shi Z, Wakil AE, Rockey DC. Strain-specific differences in mouse hepatic wound healing are mediated by divergent $\mathrm{T}$ helper cytokine responses. Proc Natl Acad Sci U S A.
1997;94(20):10663-10668.

120. Ehling J, et al. CCL2-dependent infiltrating macrophages promote angiogenesis in progressive liver fibrosis. Gut. 2014;63(12):1960-1971.

121. Ding BS, et al. Divergent angiocrine signals from vascular niche balance liver regeneration and fibrosis. Nature. 2014;505(7481):97-102.

122. Hu J, et al. Endothelial cell-derived angiopoietin-2 controls liver regeneration as a spatiotemporal rheostat. Science. 2014;343(6169):416-419.

123. Breitkopf-Heinlein K, et al. BMP-9 interferes with liver regeneration and promotes liver fibrosis. Gut. 2017;66(5):939-954.

124.Castilla A, Prieto J, Fausto N. Transforming growth factors beta 1 and alpha in chronic liver disease. Effects of interferon alfa therapy. $N$ Engl JMed.1991;324(14):933-940.

125. De Bleser PJ, Niki T, Rogiers V, Geerts A. Transforming growth factor-beta gene expression in normal and fibrotic rat liver. J Hepatol. 1997;26(4):886-893.

126. Nguyen LN, et al. Transforming growth factorbeta differentially regulates oval cell and hepatocyte proliferation. Hepatology. 2007;45(1):31-41.

127. Kordes C, Haussinger D. Hepatic stem cell niches. J Clin Invest. 2013;123(5):1874-1880.

128. Benten D, et al. Hepatocyte transplantation activates hepatic stellate cells with beneficial modulation of cell engraftment in the rat. Hepatology. 2005;42(5):1072-1081.

129. Giraudi PJ, Becerra VJ, Marin V, Chavez-Tapia NC, Tiribelli C, Rosso N. The importance of the interaction between hepatocyte and hepatic stellate cells in fibrogenesis induced by fatty accumulation. Exp Mol Pathol. 2015;98(1):85-92.

130. Malhi H, Guicciardi ME, Gores GJ. Hepatocyte death: a clear and present danger. Physiol Rev. 2010;90(3):1165-1194.

131. Jiang JX, Mikami K, Venugopal S, Li Y, Török NJ Apoptotic body engulfment by hepatic stellate cells promotes their survival by the JAK/STAT and Akt/NF- $\kappa \mathrm{B}$-dependent pathways. J Hepatol. 2009;51(1):139-148.

132. Clouston AD, Powell EE, Walsh MJ, Richardson MM, Demetris AJ, Jonsson JR. Fibrosis correlates with a ductular reaction in hepatitis C: roles of impaired replication, progenitor cells and steatosis. Hepatology. 2005;41(4):809-818.

133. Richardson MM, et al. Progressive fibrosis in nonalcoholic steatohepatitis: association with altered regeneration and a ductular reaction. Gastroenterology. 2007;133(1):80-90.

134. Roskams T, et al. Oxidative stress and oval cell accumulation in mice and humans with alcoholic and nonalcoholic fatty liver disease. Am J Pathol. 2003;163(4):1301-1311.

135. Van Hul NK, Abarca-Quinones J, Sempoux C, Horsmans Y, Leclercq IA. Relation between liver progenitor cell expansion and extracellular matrix deposition in a CDE-induced murine model of chronic liver injury. Hepatology. 2009;49(5):1625-1635.

136. Grappone C, et al. Expression of platelet-derived growth factor in newly formed cholangiocytes during experimental biliary fibrosis in rats. J Hepatol. 1999;31(1):100-109.

137. Luo B, et al. Cholangiocyte endothelin 1 and transforming growth factor $\beta 1$ production in rat 
experimental hepatopulmonary syndrome. Gastroenterology. 2005;129(2):682-695.

138. Alvaro D, et al. The intrahepatic biliary epithelium is a target of the growth hormone/insulin-like growth factor 1 axis. JHepatol. 2005;43(5):875-883.

139. Kruglov EA, Nathanson RA, Nguyen T, Dranoff JA. Secretion of MCP-1/CCL2 by bile duct epithelia induces myofibroblastic transdifferentiation of portal fibroblasts. Am JPhysiol Gastrointest Liver Physiol. 2006;290(4):G765-G771.

140.Alvaro D, et al. Proliferating cholangiocytes: a neuroendocrine compartment in the diseased liver. Gastroenterology. 2007;132(1):415-431.

141. Ruddell RG, et al. Lymphotoxin- $\beta$ receptor signaling regulates hepatic stellate cell function and wound healing in a murine model of chronic liver injury. Hepatology. 2009;49(1):227-239.

142. Yasoshima M, Kono N, Sugawara H, Katayanagi K, Harada K, Nakanuma Y. Increased expression of interleukin- 6 and tumor necrosis factor- $\alpha$ in pathologic biliary epithelial cells: in situ and culture study. Lab Invest. 1998;78(1):89-100.

143. Morland CM, Fear J, McNab G, Joplin R, Adams DH. Promotion of leukocyte transendothelial cell migration by chemokines derived from human biliary epithelial cells in vitro. Proc Assoc Am Physicians. 1997;109(4):372-382.

144. Okazaki I, Maruyama K. Collagenase activity in experimental hepatic fibrosis. Nature. 1974;252(5478):49-50.

145. Ellis EL, Mann DA. Clinical evidence for the regression of liver fibrosis. J Hepatol. 2012;56(5):1171-1180.

146.Poynard T, et al. Impact of pegylated interferon alfa- $2 \mathrm{~b}$ and ribavirin on liver fibrosis in patients with chronic hepatitis C. Gastroenterology. 2002;122(5):1303-1313.

147. Arthur MJ. Reversibility of liver fibrosis and cirrhosis following treatment for hepatitis $\mathrm{C}$. Gastroenterology. 2002;122(5):1525-1528.

148.Siller-López F, et al. Treatment with human metalloproteinase-8 gene delivery ameliorates experimental rat liver cirrhosis. Gastroenterology. 2004;126(4):1122-1133; discussion 949.

149.Iimuro $Y$, et al. Delivery of matrix metalloproteinase- 1 attenuates established liver fibrosis in the rat. Gastroenterology. 2003;124(2):445-458.

150. Saile B, Matthes N, Knittel T, Ramadori G. Transforming growth factor beta and tumor necrosis factor alpha inhibit both apoptosis and proliferation of activated rat hepatic stellate cells. Hepatology. 1999;30(1):196-202.

151. Wright MC, et al. Gliotoxin stimulates the apoptosis of human and rat hepatic stellate cells and enhances the resolution of liver fibrosis in rats. Gastroenterology. 2001;121(3):685-698.

152. Baeuerle PA, Henkel T. Function and activation of NF- $\mathrm{kB}$ in the immune system. Anпи Rev Immunol. 1994;12:141-179.

153. Mancini R, Benedetti A, Jezequel AM. An interleukin-1 receptor antagonist decreases fibrosis induced by dimethylnitrosamine in rat liver. Virchows Arch. 1994;424(1):25-31.

154.Jiao J, et al. Dendritic cell regulation of carbon tetrachloride-induced murine liver fibrosis regression. Hepatology. 2012;55(1):244-255.

155. Krämer B, et al. Natural killer p46High expression defines a natural killer cell subset that is potentially involved in control of hepatitis $\mathrm{C}$ virus replication and modulation of liver fibrosis. Hepatology. 2012;56(4):1201-1213.

156. Glässner A, et al. NK cells from HCV-infected patients effectively induce apoptosis of activated primary human hepatic stellate cells in a TRAIL-, FasL- and NKG2D-dependent manner. Lab Invest. 2012;92(7):967-977.

157. Radaeva S, Sun R, Jaruga B, Nguyen VT, Tian Z, Gao B. Natural killer cells ameliorate liver fibrosis by killing activated stellate cells in NKG2Ddependent and tumor necrosis factor-related apoptosis-inducing ligand-dependent manners. Gastroenterology. 2006;130(2):435-452.

158. Hammerich L, et al. Chemokine receptor CCR6dependent accumulation of $\gamma \delta \mathrm{T}$ cells in injured liver restricts hepatic inflammation and fibrosis. Hepatology. 2014;59(2):630-642.

159. Imamura M, Ogawa T, Sasaguri Y, Chayama K, Ueno H. Suppression of macrophage infiltration inhibits activation of hepatic stellate cells and liver fibrogenesis in rats. Gastroenterology. 2005;128(1):138-146.

160. Krizhanovsky V, et al. Senescence of activated stellate cells limits liver fibrosis. Cell. 2008;134(4):657-667.

161. Kong X, et al. Interleukin-22 induces hepatic stellate cell senescence and restricts liver fibrosis in mice. Hepatology. 2012;56(3):1150-1159.

162. Ogawa S, et al. Anti-PDGF-B monoclonal antibody reduces liver fibrosis development. Hepatol Res. 2010;40(11):1128-1141.

163. Desmet VJ, Roskams T. Cirrhosis reversal: a duel between dogma and myth. J Hepatol. 2004;40(5):860-867.

164. Rockey DC, Boyles JK, Gabbiani G, Friedman SL. Rat hepatic lipocytes express smooth muscle actin upon activation in vivo and in culture. J Submicrosc Cytol Pathol. 1992;24(2):193-203.

165. Hindley CJ, Cordero-Espinoza L, Huch M. Organoids from adult liver and pancreas: stem cell biology and biomedical utility. Dev Biol. 2016;420(2):251-261.

166. Takebe $\mathrm{T}$, et al. Vascularized and functional human liver from an iPSC-derived organ bud transplant. Nature. 2013;499(7459):481-484.

167. Drasdo D, Hoehme S, Hengstler JG. How predictive quantitative modelling of tissue organisation can inform liver disease pathogenesis. J Hepatol. 2014;61(4):951-956.

168. Rubin E, Hutterer F, Popper H. Cell proliferation and fiber formation in chronic carbon tetrachloride intoxication. A morphologic and chemical study. Am J Pathol. 1963;42:715-728.

169. Iredale JP, et al. Tissue inhibitor of metalloproteinase-1 messenger RNA expression is enhanced relative to interstitial collagenase messenger RNA in experimental liver injury and fibrosis. Hepatology. 1996;24(1):176-184.

170. Constandinou C, Henderson N, Iredale JP. Modeling liver fibrosis in rodents. Methods Mol Med. 2005;117:237-250.

171. Ala-Kokko L, Pihlajaniemi T, Myers JC, Kivirikko KI, Savolainen ER. Gene expression of type I, III and IV collagens in hepatic fibrosis induced by dimethylnitrosamine in the rat. Biochem $J$. 1987;244(1):75-79.

172. Kitamura K, et al. Pathogenic roles of tumor necrosis factor receptor p55-mediated signals in dimethylnitrosamine-induced murine liver fibrosis. Lab Invest. 2002;82(5):571-583.

173. Yoshida T, et al. SOCS1 is a suppressor of liver fibrosis and hepatitis-induced carcinogenesis. JExp Med. 2004;199(12):1701-1707.

174. Madden JW, Gertman PM, Peacock EE. Dimethylnitrosamine-induced hepatic cirrhosis: a new canine model of an ancient human disease. Sur gery. 1970;68(1):260-267; discussion 267.

175. Kawasaki S, et al. Hepatic transport of indocyanine green in dogs chronically intoxicated with dimethylnitrosamine. Toxicol Appl Pharmacol. 1984;75(2):309-317.

176. Müller A, Machnik F, Zimmermann T, Schubert $\mathrm{H}$. Thioacetamide-induced cirrhosis-like liver lesions in rats - usefulness and reliability of this animal model. Exp Pathol. 1988;34(4):229-236.

177. Salguero Palacios R, et al. Activation of hepatic stellate cells is associated with cytokine expression in thioacetamide-induced hepatic fibrosis in mice. Lab Invest. 2008;88(11):1192-1203.

178. Ding Z, Zhuo L. Attenuation of hepatic fibrosis by an imidazolium salt in thioacetamideinduced mouse model. J Gastroenterol Hepatol. 2013;28(1):188-201.

179. Fickert P, et al. A new xenobiotic-induced mouse model of sclerosing cholangitis and biliary fibrosis. Am J Pathol. 2007;171(2):525-536.

180. Tsukamoto H, Towner SJ, Ciofalo LM, French SW. Ethanol-induced liver fibrosis in rats fed high fat diet. Hepatology. 1986;6(5):814-822.

181. Ki SH, et al. Interleukin-22 treatment ameliorates alcoholic liver injury in a murine model of chronic-binge ethanol feeding: role of signal transducer and activator of transcription 3. Hepatology. 2010;52(4):1291-1300.

182. Popper H, Lieber CS. Histogenesis of alcoholic fibrosis and cirrhosis in the baboon. Am J Pathol. 1980;98(3):695-716.

183. Knight B, et al. Attenuated liver progenitor (oval) cell and fibrogenic responses to the choline deficient, ethionine supplemented diet in the BALB/cinbred strain of mice.JHepatol. 2007;46(1):134-141.

184. Hacker HJ, Steinberg P, Toshkov I, Oesch F, Bannasch P. Persistence of the cholangiocellular and hepatocellular lesions observed in rats fed a choline-deficient/DL-ethionine-supplemented diet. Carcinogenesis. 1992;13(2):271-276.

185. Vizzutti F, et al. Curcumin limits the fibrogenic evolution of experimental steatohepatitis. Lab Invest. 2010;90(1):104-115.

186.Webster GT. Cirrhosis of the liver among rats receiving diets poor in protein and rich in fat. J Clin Invest. 1942;21(4):385-392.

187. Mu YP, Ogawa T, Kawada N. Reversibility of fibrosis, inflammation, and endoplasmic reticulum stress in the liver of rats fed a methionine-choline-deficient diet. Lab Invest. 2010;90(2):245-256.

188. Yang L, et al. Fate-mapping evidence that hepatic stellate cells are epithelial progenitors in adult mouse livers. Stem Cells. 2008;26(8):2104-2113.

189.Issa R, et al. Apoptosis of hepatic stellate cells: involvement in resolution of biliary fibrosis and regulation by soluble growth factors. Gut. 2001;48(4):548-557.

190.Symeonidis A, Trams EG. Morphologic and func- 


\section{REVIEW SERIES: FIBROSIS}

tional changes in the livers of rats after ligation or excision of the common bile duct. Am J Pathol. 1957;33(1):13-27.

191. Ohlsson EG, Rutherford RB, Boitnott JK, Haalebos MM, Zuidema GD. Changes in portal circulation after biliary obstruction in dogs. Am J Surg. 1970;120(1):16-22.

192.Rutherford RB, Boitnott JK, Donohoo JS, Ohlsson EG, Sebor J, Zuidema GD. The production of biliary cirrhosis in Macaca mulatta monkeys. Arch Surg. 1970;100(1):55-60.

193. Ueberham E, Löw R, Ueberham U, Schönig K, Bujard H, Gebhardt R. Conditional tetracyclineregulated expression of TGF- $\beta 1$ in liver of transgenic mice leads to reversible intermediary fibrosis. Hepatology. 2003;37(5):1067-1078.

194. Kanzler S, et al. TGF- $\beta 1$ in liver fibrosis: an inducible transgenic mouse model to study liver fibrogenesis. Am JPhysiol.1999;276(4 pt 1):G1059-G1068.

195. Czochra P, et al. Liver fibrosis induced by hepatic overexpression of PDGF-B in transgenic mice. J Hepatol. 2006;45(3):419-428.

196. Mauad TH, et al. Mice with homozygous disruption of the mdr2 P-glycoprotein gene. A novel animal model for studies of nonsuppurative inflammatory cholangitis and hepatocarcinogenesis. Am J Pathol. 1994;145(5):1237-1245.

197. Luedde T, et al. Deletion of NEMO/IKK $\gamma$ in liver parenchymal cells causes steatohepatitis and hepatocellular carcinoma. Cancer Cell. 2007;11(2):119-132.

198. Bettermann K, et al. TAK1 suppresses a NEMOdependent but NF-kB-independent pathway to liver cancer. Cancer Cell. 2010;17(5):481-496.

199. Takehara T, et al. Hepatocyte-specific disruption of Bcl-xL leads to continuous hepatocyte apoptosis and liver fibrotic responses. Gastroenterology. 2004;127(4):1189-1197.

200.Wu SJ, et al. Innate immunity and primary biliary cirrhosis: activated invariant natural killer $\mathrm{T}$ cells exacerbate murine autoimmune cholangitis and fibrosis. Hepatology. 2011;53(3):915-925. 